\title{
Granone's Plastic Monoideism Demonstrated by Functional Magnetic Resonance Imaging (fMRI)
}

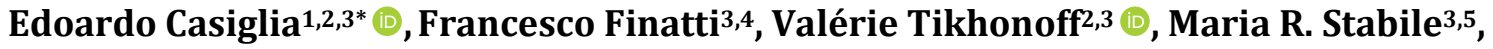 \\ Micaela Mitolo ${ }^{5,6}$, Federica Gasparotti2,3, Federica Albertini2,7, Antonio M. Lapenta ${ }^{3}$, \\ Annalena Venneri8
}

\author{
${ }^{1}$ Studium Patavinum, University of Padova, Padova, Italy \\ ${ }^{2}$ Department of Medicine, University of Padova, Padova, Italy \\ ${ }^{3}$ Institute Franco Granone, Italian Centre of Clinical and Experimental Hypnosis, Torino, Italy \\ ${ }^{4}$ School of Pathology, University of Padova, Padova, Italy \\ ${ }^{5}$ Department of Neurorehabilitation, Foundation Hospital San Camillo, Venice, Italy \\ ${ }^{6}$ Functional Magnetic Resonance Unit, Hospital S. Orsola-Malpighi, Bologna, Italy \\ ${ }^{7}$ School of Emergency Medicine, University of Padova, Padova, Italy \\ ${ }^{8}$ Department of Neuroscience, University of Sheffield, Sheffield, UK \\ Email:*edoardo.casiglia@unipd.it, francesco.finatti@studenti.unipd.it, valerie.tikhonoff@unipd.it, \\ mariarosaria.stabile@ospedalesancamillo.it,federica.albertini@studenti.unipd.it,federica ga sparotti@unipd.it, \\ ciics@seleneweb.com,micaela.mitolo@unibo.it, a.venneri@sheffield.ac.uk
}

How to cite this paper: Casiglia, E., Finatti, F., Tikhonoff, V., Stabile, M. R., Mitolo, M., Gasparotti, F., Albertini, F., Lapenta, A. M., \& Venneri, A. (2019). Granone's Plastic Monoideism Demonstrated by Functional Magnetic Resonance Imaging (fMRI). Psychology, 10, 434-448.

https://doi.org/10.4236/psych.2019.104030

Received: February 9, 2019

Accepted: March 4, 2019

Published: March 7, 2019

Copyright $\odot 2019$ by author(s) and Scientific Research Publishing Inc. This work is licensed under the Creative Commons Attribution International License (CC BY 4.0).

http://creativecommons.org/licenses/by/4.0/

\begin{abstract}
Plastic monoideism is the supposed basis of hypnosis, but has never been experimentally demonstrated. The aim of the paper presented herein is to demonstrate that plastic monoideism exists and can be put in evidence by functional magnetic resonance (fMRI). To this aim, fMRI brain areas activation was examined in 20 highly hypnotizable young participants during a task represented by hypnotic analgesia. Inhibition of pain transmission from periphery to brain cortex was demonstrated during hypnotic analgesia by lack of activation of central somatosensory areas. At the same time, the Brodmann areas 9, 25, 32 and 47 were highly activated. This indicates that during a hypnotic task the iper-activity of certain brain areas inhibits the other ones. This is just, for the neurobiologist, what plastic monoideism is for the clinic hypnotist. The hyper-activated areas represent the physiological basis of the monoideism, which was therefore confirmed by brain imaging.
\end{abstract}

\section{Keywords}

Hypnosis, Functional Magnetic Resonance, Neuroimaging, Hypnotic Task, Plastic Monoideism, Granone 


\section{Introduction}

For the Franco Granone's School (Granone, 1962, 1972, 1989; Casiglia, 2015), the basis of hypnotic trance is the so-called "plastic monoideism" (Casiglia, 2012), i.e. the realization of a mental image leading - thanks to the hypnotic condition-to a so high level of concentration and intensity to become "plastic", in other words able to produce both psychic (Casiglia et al., 2010b, 2012a, 2012b, 2015, 2016b; Casiglia \& Mentesana, 2018; Casiglia \& Tikhonoff, 2015; Facco et al., 2014, 2017, 2019; Giordano et al., 2012; Tikhonoff et al., 2018) and physical (Casiglia et al., 2015, 2016a, 2018a; Casiglia \& Mentesana, 2018; Casiglia \& Mentesana, 2007; Tikhonoff et al., 2018) effects. As previously demonstrated by our School (Casiglia et al., 2012a, 2012b, 2018a; Tikhonoff et al., 2018) and by other Authors (Beevi et al., 2017; Dittrich et al., 2018; Halsband \& Wolf, 2015), hypnosis sustained by plastic monoideism, reverberating at a psychosomatic level (Granone, 1962, 1972, 1989; Casiglia, 2015), is therefore an excellent way to study experimentally both mind and body, and a precious tool in the hand of researchers (Casiglia et al., 1994, 2012a).

A monoideism can occur spontaneously in everyday life or following particular situations, such as monotony, a trauma or another cause of dissociation (Granone, 1989; Casiglia, 2015; Eckhardt et al., 2018; Loewenstein, 2018), but is more intense and plastic when produced by the rapport with an expert hypnotist in a clinical or experimental context (Casiglia, 2015).

Up to date, the plastic monoideism hypothesized by Granone has never been demonstrated in experimental setting but only supposed and indirectly observed in its effects. This is due to many factors, such as 1) the lack of interest for this topic by the psychologists, 2) the mainly practical attitude of psychotherapists (more centered on the effects of the phenomenon than on its mechanisms), 3) the difficulty to access functional magnetic resonance imaging (fMRI), 4) the ned for a deep hypnosis, and 5) the fact that plastic monoideism can only be demonstrated during a task, because as a matter of fact it does not appear in the default mode. The demonstration of plastic monoideism is therefore a demanding and expensive challenge requiring a trained staff acting in a rigid experimental setting. This delayed the demonstration of plastic monoideism.

Lacking of this demonstration makes uncomfortable the scientists who are trying to ferry hypnosis from the category of narrative psychology to that of Galilean science. The research group represented by the Laboratory of Experimental Hypnosis of the University of Padova acting in concert with the Institute Franco Granone of Torino has always been particularly active in this field, using to this aim bot experimental models and technological devices that are normally and typically employed in classic human physiology (Casiglia et al., 2012a, 2012b, 2016b, 2018a, 2018b; Casiglia \& Mentesana, 2018).

The aim of the study shown herein is to ascertain whether plastic monoideism really exists and, if so, to make it substantial thanks to neuroimaging.

\section{Methods}

Theoretical basis. Despite the large use of hypnosis in clinical, experimental 
and sport settings, the theoretical basis of hypnosis are uncertain and incomepletely defined (Elkins et al., 2015). The most accredited theory is that hypnosis represents a sort of regression (Casiglia, 2012), requires empathy leading to a rapport (Wickramasekera, 2015), and implies mental dissociation (Eckhardt et al., 2018; Lynn \& Green, 2011). In hypnosis, the participant is more prone to accept critically the idea of the operator (Casiglia \& Rossi, 2008). Although a little reduced in its intensity, critical mind is still operating in hypnosis (Casiglia, 2011, 2015), making hypnosis different from suggestion. Nevertheless, the neuro-physiological mechanisms that are at the basis of hypnosis are largely unknown (Jamieson \& Burgess, 2014; Landry et al., 2017) and need to be experimentally investigated (Wall, 2018).

Experimental model. For the experiment described herein, the following mental model was used. First, participants underwent fMRI to measure the intensity of activation of brain areas during a task (pain) out of hypnosis. In a second session, the same participants repeated the exam being involved in the same task after producing hypnotic analgesia in an intra-subject latin-square protocol in which each participant was control of him/herself. In previous experiments, we had already demonstrated that hypnotic analgesia exists for both non-trieminal (systemic) and trigeminal pain and is a real, measurable and repeatable phenomenon (Casiglia et al., 2007, 2012a, 2015, 2018a; Facco et al., 2009, 2011, 2013, 2011a, 2018), and that hypnosis is an excellent way to study not only the mind but also the body (Casiglia et al., 2012a; Tikhonoff et al., 2012). Briefly, these experiments were performed by means of sympathetic and parasympathetic tests (Ibrahim, 1975) whose characteristic is to produce consequences on cardiovascular system. Non-trigeminal (systemic) pain induces an increase in central and peripheral arterioral resistance (Casiglia et al., 2007; Ibrahim, 1975; Peckerman et al., 1991, 1994), while trigeminal pain reduces resistance (Casiglia et al., 2018c; Facco et al., 2009, 2011). We demonstrated that hypnotic analgesia obtained by direct suggestion of absence of pain (Casiglia et al., 2018c) or by body dysmorphism (Casiglia et al., 2016a) decreased and in many cases abolished not only subjective feeling of pain but also the resistance variation, independent of it was in plus or in minus, so showing pain was really blocked at a certain level of nervous system and not simply dissociated by consciousness. These experiments are summarized and detailed in an article by our research group appeared in a recent issue of Psychology (Casiglia et al., 2018c). Nevertheless, in the experiment described herein, hypnotic analgesia was used not per se but only as a task to produce a plastic monoideism.

Ethics and safety measures. The study was approved by the Ethics Committee of the University Hospital in Padova (Italy) and by that of the Fondazione Ospedale San Camillo in Venice (Italy) where fMRI scanning took place.

The study was performed according to the Declaration of Helsinki for Human Research (41 ${ }^{\text {st }}$ World Medical assembly, 1990). Each subject was previously and personally informed about the aim, the meaning and the possible risks of the procedure, and was free to ask all the questions they felt necessary to have a full 
comprehension of it. All the subjects gave a valid informed consent and signed a form approved by the Ethics Committee according to Italian law 675/1996 and to the law of the Veneto Region 34/2007.

Participants were informed that the aim of the study was to investigate the functional differences between the cerebral areas activated during painful stimuli before and during hypnotic analgesia. They were also informed that during the random acquisition process, once inside the scanner, they would have to remain still with their eyes open and listen to the instructions given by the hypnotist thought the headphones.

The hypnotist did not enter the fMRI room but was constantly in contact with the subject via an intercom and monitored their conditions from the adjacent room. In a recent experimental study, we demonstrated that both induction and maintenance of deep hypnosis are possible atdistance, by means of an electronicdevice (Casiglia et al., 2018a).

Participants. Twenty healthy volunteers whose general characteristics are shown in Table 1 were studied. All were classified as highly hypnotizable on the basis of the Stanford Hypnotic Susceptibility Scale Form A (De Pascalis, Russo, \& Marucci, 2000) and were judged fit for hypnosis by means of an anamnestic questionnaire, of a confidential interview with the principal investigator and, when necessary, of Minnesota Multiphasic Personality Inventory 2 Restructured Form (Locke, 2013). This procedure was aimed at screening the subjects with a borderline personality who could be more prone to develop side effects during hypnosis.

Preliminary setting. In the preliminary setting, all subjects underwent individual hypnotic induction through verbal suggestions. The aim of this preparatory procedure was to establish a valid interpersonal rapport between the operator and the subject, in order to promote a rapid and valid monoideism during the following experimental setting. The voice of an expert hypnotist guided each subject towards focusing their attention on a single idea, excluding any other external or internal stimulus. Hypnotic induction consisted of a brief enumeration coupled with suggestions of eyelid heaviness and staring at a point.

The verification of hypnosis was based on some signals, such as arm levitation, the easing of facial tension, a dropping of the lower jaw with a slight opening of the mouth, and the slowing down of breathing rate. This phenomenological approach was sufficient to ascertain the presence of deep hypnosis. The analysis of these signals allowed the hypnotist to verify whether the subjects were really hypnotised and to maintain or modify this condition by means of continuous appropriate suggestions.

A post-hypnotic suggestion was left to each subject in order to obtain rapid and deep hypnotic trance subsequently in the experimental setting. The aim of this command was to reduce the time needed for further inductions. In order to obtain this, subjects were given the suggestion to immediately reach hypnosis when receiving the command "please, [name], relax". The effectiveness of this 
Table 1. General characteristic of study participants relevant for the experiment.

\begin{tabular}{cc}
\hline Parameters & Values \\
\hline Age (years) & $30 \pm 1$ \\
Sex (males/females) & $5 / 15$ \\
Schooling level (years) & $18.1 \pm 2.6$ \\
Hypnotizability (Stanford score, De Pascalis, Russo, \&Marucci, 2000) & $9 \pm 1$ \\
\hline
\end{tabular}

conditioning was tested immediately before the end of the session. The subject was then de-hypnotised and sent home.

Experimental setting. The subjects then underwent the experimental fMRI procedure.

fMRI records signals, which depend on local variations in the concentration of deoxyhaemoglobin, in turn show the areas that are activated by a task or a condition (Buxton \& Frank, 1997). The signal produced in basal conditions can be compared to that produced during a HFA task, thus creating activation maps reporting the brain areas that are involved in the different states.

Hypnosis was obtained and maintained at distance when the subject was in the fMRI scanner (Casiglia \& Mentesana, 2018) through post-hypnotic conditioning.

Each fMRI session lasted about 1 hour. Once the participant was inside the scanner, his/her head was immobilized using foam padding and a head band to minimize movements. Good comprehension of the procedure was ascertained, and headphones were placed on their ears to ensure a connection with the external environment (Casiglia et al., 2018a). Experimental instructions were presented on a display and projected via the Nordic Neurolab fibre optic visual presentation device mounted over the scanner head coil. Visual acuity was adjusted to individual needs. Pain was obtained via a cold pressor test (Ibrahim, 1975; Peckerman et al., 1991, 1994; Freeman et al., 2000) by immersing left hand in a container of icy water at $0^{\circ} \mathrm{C}\left(32^{\circ} \mathrm{F}\right)$ temperature placed in the fMRI, analgesia by direct suggestions given in hypnosis (Casiglia et al., 2007, 2012a, 2015, 2016a, 2018a; Facco et al., 2009, 2011, 2011a, 2018). Scans were acquired on a 1.5 T Philips Achieva MRI system, fitted with a Sense head coil. The scanning protocol included the acquisition of a T1-weighted structural scan, four functional scans, a T2-weighted axial scan, and a fluid attenuated inversion recovery (FLAIR) scan. Total imaging time, including localisation and structural image acquisitions, was approximately sixty minutes. Echo planar single shot $\mathrm{T}^{*}$ weighted MRI images $\left(\mathrm{TR}=2 \mathrm{~s}, \mathrm{TE}=50 \mathrm{~ms}\right.$, flip angle $=90^{\circ}$, voxel dimensions $3.28 \times 3.28 \times 5.00 \mathrm{~mm}$, field of view $240 \mathrm{~mm}$ ). 252 volumes of 30 contiguous axial slices were acquired in ascending order in each run. Each run was preceded by 30 seconds of dummy scans to allow the scanner to reach equilibrium. Total scanning time including structural scans was 59 minutes and 32 seconds. As in other experiment performed by our research group (Casiglia \& Mentesana, 2018), the Statistical Parametric Mapping 12 (SPM12) package (Wellcome Centre 
for Human Neuroimaging, London, UK) was used in a Matlab environment on a Linux interface both for image pre-processing and statistical analysis. The pre-processing phase included slice timing, realignment, normalization and spatial smoothing. For each voxel, slice-timing correction examined the time course and slightly moved it by interpolating with each other the points that were really detected in order to give the amount of time that would have been obtained if each voxel had been recorded exactly at the same time. The algorithm for slice-timing correction uses an interpolation synchronized between time points, obtained through a Fourier's transform of the signal of each voxel. During pre-processing, all volumes of each subject were corrected by the slice-timing using the $15^{\text {th }}$ image as the reference slice (ascending acquisition). Slices were then realigned to their own mean according to the SPM12 protocol and then resliced through a $4^{\text {th }}$ degree B-spline interpolation to correct the residual movement due to signal changes. The realigned scans were normalized in a first attempt to superimpose each brain to the common template. The filter REST (part of the SPM12 toolbox) was applied after normalization but before spatial smoothing with a $6 \times 6 \times 6 \mathrm{~mm}$ width at half maximum isotropic Gaussian kernel to compensate for any residual variability after spatial normalization. Movement parameters were included as regressors in the analysis, although no subjects showed movement exceeding $2 \mathrm{~mm}$. The analytical phase included a first and a second level analysis. During the first level analysis, all the runs of each subject were put together in a multiple analysis using a general linear model. Image data were high-pass filtered with a set of discrete cosine basis functions with a cut-off period of $200 \mathrm{~s}$. This passage generated a series of contrasts where EPI sequences during HFA were compared to EPI sequences without HFA. Contrast images generated at this level where then entered in one-sample t-tests. For all models, the significance threshold was set at $p<0.005$ (uncorrected) at the set level, and $p<0.05$ (family-wise error-corrected) at the cluster level. Resulting $\mathrm{x}, \mathrm{y}, \mathrm{z}$ coordinates in the MNI space using models of standard brains from the Montreal Neurological Institute were converted into the Talairach space by a non-linear transformation and localised using the Talairach Daemon client (http://www.talairach.org/client.html). Differences were found comparing the pattern "immerse/rest" during HFA and during non-hypnosis. Images are presented herein according to the neurological convention, where right indicates the right hemisphere and left the left hemisphere.

\section{Results}

fMRI data analysis. In conditions of usual consciousness (Casiglia et al., 2010a), the "task in basal conditions without hypnosis" was associated to significant activation in Brodmann's areas (BA) 1, 2, 3 (also colled primary sensory areas), 4, 6, 7, 9, 11, 25, 34, 40 and 47 was observed. Table 2 (upper panel) summarizes the intensity of the signals and the Talairach coordinates of these areas. During the "task in hypnosis", only the BA 9 (frontal medial gyrus), BA 25 
Table 2. Areas of significant activation during a task (in the present experiment, pain without and with hypnotic focus analgesia). BA: Brodmann areas. In hypnosis the active areas are limited in number (BA 9, 25, 32 and 47) and their activation is greater than in basal conditions. Tailarachcoordinates of BA are also indicated.

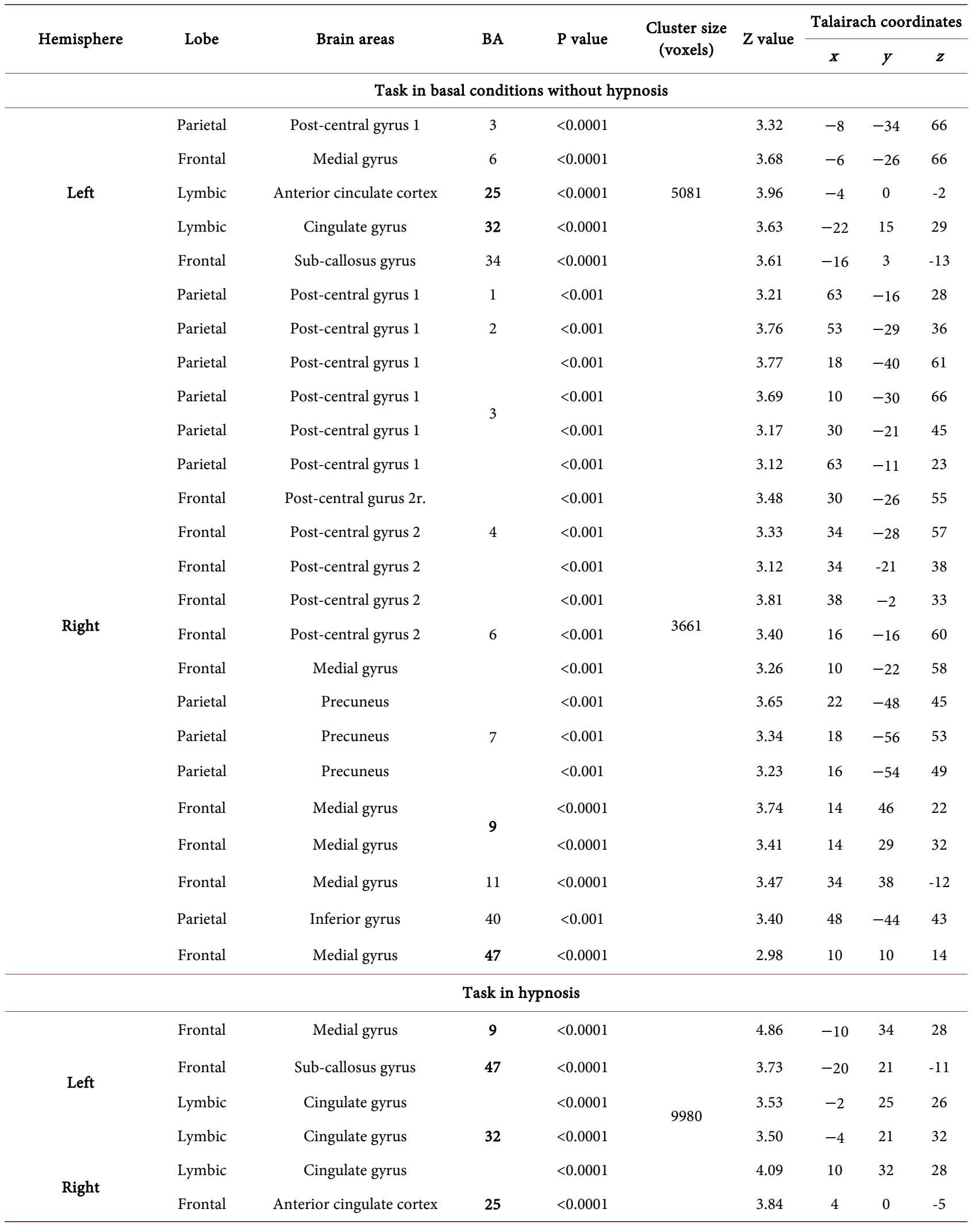


(anterior cingulate cortex), BA32 (cingulate gyrus) and BA 47 (sub-callosus gyrus) were activated (Table 2, lower panel) - and more activated than in basal conditions-as well as thecaudatum and of the cerebellum, while the other ones were silent. These areas are shown in green and in red, respectively, in Figure 1.

The two experimental conditions were identical, safe for hypnosis.

The artificial rendering built in Figure 2 shows the brain cortex activation in the two conditions "task in basal conditions without hypnosis" and "task in hypnosis"). As in Figure 1, the areas in green are those active in the task without hypnosis, while those in red are active in the task with hypnosis, as if the two conditions were present at the same time. The two conditions have no point of contact. The figure is defined artificial just because the two conditions (nonhypnosis and hypnosis) are mutually exclusive and could never appear in the same image: the second exclude the first.

\section{Discussion}

Plastic monoideism is the condicio sine qua non of hypnosis: no monoideism, no hypnosis. Franco Granone (1911-2000), the neuropsychiatrist who introduced medical hypnosis in Italy, based his entery theory of hypnosis on plastic monoideism in a period in which, unfortunately, no technology existed to demonstrate this theory had solid bases. Plastic monoideism as the key factor allowing hypnosis was therefore accepted as a dogma, based on its evident effects. When a person is induced to hypnosis, he/her develops a monoideism that becomes plastic, i.e. able to produce not only psychic but also physical effects. In 25 years of experience on the field, the Laboratory of Experimental Hypnosis of the University of Padova and of the Italian Centre of Clinical and Experimental Hypnosis directed by one the authors of the present paper (E.C.) demonstrated that in condition of plastic monoideism it is easy to produce conditions such as neglects (Priftis et al., 2011; Casiglia et al., 2010b; Facco et al., 2014), hallucinations (Casiglia et al., 2007; Facco et al., 2019), paralysis (Casiglia \& Mentesana, 2018), local analgesia (Casiglia et al., 2007, 2012a, 2015, 2016a, 2018a; Facco et al., 2009, 2011, 2011a, 2018), general anaesthesia (Casiglia et al., 2015), vasodilation or vasoconstriction (Casiglia et al., 2007, 2012b; Facco et al., 2011a; Tikhonoff et al., 2018), increase of psychic (Casiglia \& Tikhonoff, 2015) and physical (Tikhonoff et al., 2012) performance, and many other effect such as relaxation, amnesia, and so on. No substances were used to obtain these experimental effects, so that the plastic monoideism, acting at an unconscious level (Casiglia et al., 2016b; Solms, 2017), had to be the only factor responsible for them.

Due to lack of information about its anatomical bases, plastic monoideism could not be localized, visualized or even imagined in its nature, and was often confused with mere mental dissociation.

Recently, fMRI opened new ways in the study of human mind. In fact, fMRI is capable to verify the activation of specific cortical areas (Belliveau et al., 1991; Oakley et al., 2007; Pyka et al., 2011) and is reliable, repeatable, non-invasive and approved by the international scientific community (Glover, 2011; 

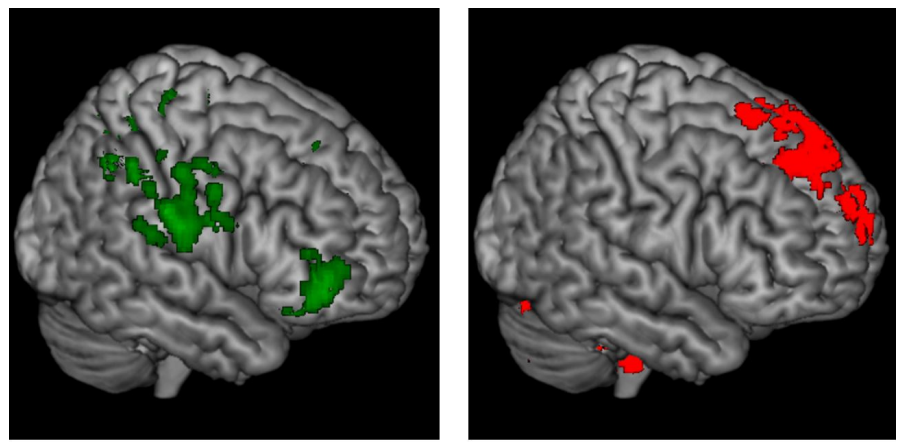

Figure 1. Funtional magnetic resonance imaging during a task (pain), both in basal conditions without hynosys (left panel) and during hypnotic analgesia (right panel). The cerebral areas in green are those activated by pain, the areas in red are those activated by hypnosis. See text for the denominations of the areas.
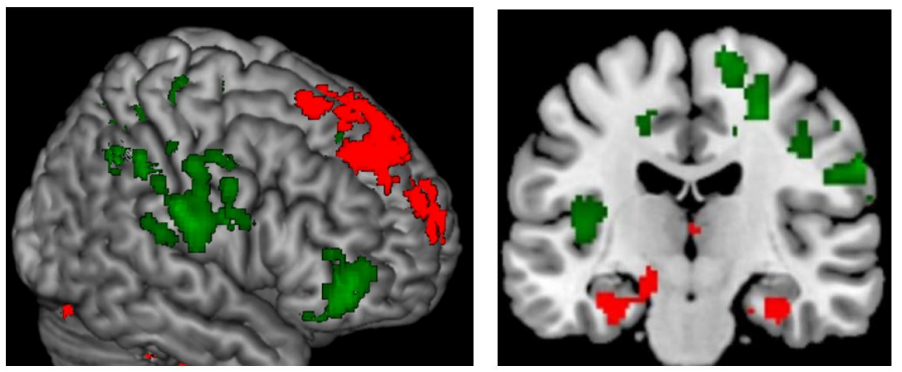

Figure 2. Artificial rendering showing in the same image the two condition (pain and hypnosis). As one can observe, the two conditions are mutually exclusive. Left panel: lateral view. Right panel: inferior view. The hypnotic condition (in red) is plastic monoideism able to nullify pain (in green). The red areas represent the fMRI graphic model of plastic monoideism.

Ray \& Oathes, 2003; Stikova, 2012). Two of the authors of the present paper (A.V. and E.C.) previously used successfully fMRI in hypnotic experimental setting (Casiglia et al, 2018b; Mazzoni et al., 2013; McGeown et al., 2009, 2012, 2015).

In the present paper, fMRI was used to demonstrate that plastic monoideism exists and can be put in evidence with the methods that are typical of human physiology. In experimental setting, highly hypnotizable participants underwent the same task, first in usual condition (no hypnosis) and then in hypnosis (the nature of the task, here represented by pain, has no importance, being nothing more than the condition necessary to put in evidence the monoideism). The results demonstrated that, when hypnosis was present, the brain areas activated by hypnosis were completely different from those that were active out of hypnosis. Not only this, but the two categories of areas (those out of hypnosis and those in hypnosis) had no point of contact. In other words, the hypnotic condition excluded the usual brain activation, taking the control of brain cortex. Figure 1 and even better the artificial rendering in Figure 2 clearly show this evidence: when hypnosis is present (red color), the usual brain activity due to pain (green 
color) is absent. In the experiment shown herein, some areas that were previously poorly activated (the BA 9, BA 37 and BA 42 in the left hemisphere and the BA 25 and BA 32 in the right hemisphere) were the only ones in activity during hypnosis and were more active than in conditions of usual consciousness.

Now, the BA 9, BA 25, BA 32 and BA 47 are those which are commonly associated to egoic consciousness, voluntary processes (Casiglia \& Mentesana, 2018; Solms, 2017), empathy (Farrow et al., 2001), comprehension of language (Lauro et al., 2008), self-criticism (Longe et al., 2010) and control of negative emotions (Kerestes et al., 2012), i.e. the main functions of superior brain activity. BA 25 (genual part of the cingulate cortex) participates in or even co-ordinates the network amygdala $\leftrightarrow$ insula $\leftrightarrow$ hippocampus $\leftrightarrow$ memory $\leftrightarrow$ associative frontal cortex, a circuit that is linked to self-evaluation (Insel, 2010), while BA 32 (dorsal part of the anterior cingulate cortex) is involved in representing "their own and others' mental status" (Mazza et al., 2008) and in metaphor appreciation (Casiglia, 2012). BA 47 (orbital portion of the inferior frontal circumvolution) is involved in selective attention, sensory $\leftrightarrow$ integration, working memory and reasoning. Finally, the frontal/prefrontal cortex and its association to the BA 9 are the basis of voluntary actions (Farrer et al., 2003; Nahab et al., 2011; Fukushima et al., 2013; Kang et al., 2015). The plastic monoideism is therefore founded on the same brain areas that build the Homo sapiens's mental activity.

The task used in the present experiment was hypnotic analgesia. It is note worthy to observe that the BA areas 1,2 and 3 were inactive when the BA 9, BA 25, BA 32 and BA 47 were activated (better, hyper-activated) by hypnosis. This demonstrate that hypnotic analgesia is not represented by the passive disconnection of the sensory areas, but is an active phenomenon due to hyper-functioning of the areas that are typical of the sapiens's superior mind.

This is just the effect of the monoideism, becoming the preeminent or better the exclusive function during hypnotic trance, and constituting de facto the trance itself, extinguishing all other activities including - in the present taskthose of the sensory areas.

Two limitations of the present study are that it was performed on highly hypnotizable participants only and that its protocol was not conceived to clarify if suggestions administered outside the context of hypnosis or distraction techniques were effective as well. The so-called echo-genetic context (Stolarz et al., 2004; Tikhonoff et al., 2003), not explored in the present study, should also be taken into account.

Further studies in these fields are mandatory to answer these open questions.

\section{Conflicts of Interest}

The authors declare no conflicts of interest regarding the publication of this paper.

\section{References}

Beevi, Z., Low, W. Y., \& Hassan, J. (2017). The Effectiveness of Hypnosis Intervention for 
Labor: An Experimental Study. American Journal of Clinical Hypnosis, 60, 172-191. https://doi.org/10.1080/00029157.2017.1280659

Belliveau, J. W., Kennedy Jr., D. N., McKinstry, R. C., Buchbinder, B. R., Weisskoff, R. M., Cohen, M. S., Vevea, J. M. et al. (1991). Functional Mapping of the Human Visual Cortex by Magnetic Resonance Imaging. Science, 254, 716-719. https://doi.org/10.1126/science.1948051

Buxton, R. B. \& Frank, L. R. (1997). A Model for the Coupling between Cerebral Blood Flow and Oxygen Metabolism during Neural Stimulation. Journal of Cerebral Blood Flow and Metabolism, 17, 64-72. https://doi.org/10.1097/00004647-199701000-00009

Casiglia, E. (2011). Decision, Volition and Free Will. Padova: Libraria Padovana Editrice.

Casiglia, E. (2012). Why Is It So Easy to Hypnotize? Contemporary Hypnosis and Integrative Therapy, 29, 309-314.

Casiglia, E. (2015). Trattato d'ipnosi e altre modificazioni di coscienza. Padova: CLEUP.

Casiglia, E., \& Mentesana, L. (2018). Instrumental Demonstration of Hypnotic Flaccid Paralysis of Corrugator Muscles and Its Use in Esthetic Medicine. Sleep and Hypnosis, 20, 60-66.

Casiglia, E., \& Rossi, A. M. (2008). Theory and Practice of Hypnosis. Padova: Libraria Padovana Editrice.

Casiglia, E., \& Tikhonoff, V. (2015). Aumento delle prestazioni psichiche. In E. Casiglia (Ed.), Trattato d'ipnosi e altre modificazioni di coscienza (pp. 617-621). Padova: CLEUP.

Casiglia, E., Albertini, F., Tikhonoff, V., Gasparotti, F., Favaro, J., Finatti, F., Rempelou, P. et al. (2018a). Experimental Approach to the Transmission of Information in Hypnosis. Psychology, 9, 1-13. https://doi.org/10.4236/psych.2018.91001

Casiglia, E., Facco, E., \& Rossi, A. M. (2010a). The Worlds of Consciousness. Padova: Libreria Padovana Editrice.

Casiglia, E., Finatti, F., Gasparotti, F., Stabile, M. R., Mitolo, M., Albertini, F., Lapenta, A. M. et al. (2018b). Functional Magnetic Resonance Imaging Demonstrates That Hypnosis Is Conscious and Voluntary. Psychology, 9, 1571-1581.

https://doi.org/10.4236/psych.2018.97095

Casiglia, E., Rempelou, P., Tikhonoff, V., Giacomello, M., Finatti, F., Albertini, F., Favaro, J. et al. (2016a). Hypnotic Focused Analgesia Obtained through Body Dysmorphism Prevents both Pain and Its Cardiovascular Effects. Sleep and Hypnosis, 19, 89-95.

Casiglia, E., Rempelou, P., Tikhonoff, V., Guidotti, F., Pergher, V., Giordano, N., Testoni, I. et al. (2015). Hypnotic General Anesthesia vs. Focused Analgesia in Preventing Pain and Its Cardiovascular Effects. Athens Journal of Health, 3, 145-158.

https://doi.org/10.30958/ajh.3-2-2

Casiglia, E., Rossi, A., Mazza, A., Cavattoni, G., Colangeli, G., Ginocchio, G., Di Menza, G. et al. (1994). Hypnosis as a Tool for Evaluating the Cortical Component of Haemodynamic Variations. Pilot Study during Blood Letting. High Blood Pressure and Cardiovascular Prevention, 3, 8.

Casiglia, E., Schiavon, L., Tikhonoff, V., Haxhi Nasto, H., Azzi, M., Rempelou, P., Giacomello, M. et al. (2007). Hypnosis Prevents the Cardiovascular Response to Cold Pressor Test. American Journal of Clinical Hypnosis, 49, 255-266.

https://doi.org/10.1080/00029157.2007.10524503

Casiglia, E., Schiff, S., Tikhonoff, V., Schiavon, L., Bascelli, A., Haxhi Nasto, H., Facco, E. et al. (2010b). Neurophysiological Correlates of Post-Hypnotic Alexia. A Controlled Study with Stroop Test. American Journal of Clinical Hypnosis, 52, 219-234. 
https://doi.org/10.1080/00029157.2010.10401721

Casiglia, E., Tikhonoff, V., \& Facco, E. (2016b). The Unconscious Experimentally Demonstrated by Means of Hypnosis. Psychology, 7, 469-479.

https://doi.org/10.4236/psych.2016.74048

Casiglia, E., Tikhonoff, V., Albertini, F., Lapenta, A. M., Gasparotti, F., Finatti, F., Rossi, A. M. et al. (2018c). The Mysterious Hypnotic Analgesia: Experimental Evidences. Psychology, 9, 1935-1956. https://doi.org/10.4236/psych.2018.98112

Casiglia, E., Tikhonoff, V., Giordano, N., Andreatta, E., Regaldo, G., Tosello, M. T., Rossi, A. M. et al. (2012a). Measured Outcomes with Hypnosis as an Experimental Tool in a Cardiovascular Physiology Laboratory. International Journal of Clinical and Experimental Hypnosis, 60, 242-261. https://doi.org/10.1080/00207144.2012.648078

Casiglia, E., Tikhonoff, V., Giordano, N., Regaldo, G., Facco, E., Marchetti, P., Schiff, S. et al. (2012b). Relaxation versus Fractionation as Hypnotic Deepening: Do They Differ in Physiological Changes? International Journal of Clinical and Experimental Hypnosis, 60, 338-355. https://doi.org/10.1080/00207144.2012.675297

De Pascalis, V., Russo, P., \& Marucci, F. S. (2000). Italian Norms for the Harvard Group Scale of Hypnotic Susceptibility, Form A. International Journal of Clinical and EXperimental Hypnosis, 48, 44-55. https://doi.org/10.1080/00207140008410360

Dittrich, N., Agostino, D., Antonini Philippe, R., Guglielmo, L. G. A., \& Place, N. (2018). Effect of Hypnotic Suggestion on Knee Extensor Neuromuscular Properties in Resting and Fatigued States. PLOS ONE, 13, e0195437. https://doi.org/10.1371/journal.pone.0195437

Eckhardt, A., Zambrano, E. A., \& Nilsson, D. (2018). Traumatic Experiences and Dissociation in a Non-Clinical Group of University Students in Ecuador: A CrossSectional Study. Journal of Child Adolescent Mental Health, 30, 191-202. https://doi.org/10.2989/17280583.2018.1553780

Elkins, G. R., Barabasz, A. F., Council, J. R., \& Spiegel, D. (2015). Advancing Research and Practice: The Revised APA Division 30 Definition of Hypnosis. International Journal of Clinical and Experimental Hypnosis, 63, 1-9. https://doi.org/10.1080/00207144.2014.961870

Facco, E., Casiglia, E., Al Khafaji, B. E., Finatti, F., Duma, G. M., Mento, G., Pederzoli, L. et al. (2019). The Neurophenomenology of Out-of-Body Experiences Induced by Hypnotic Suggestions. International Journal of Clinical and Experimental Hypnosis, 67, 39-68. https://doi.org/10.1080/00207144.2019.1553762

Facco, E., Casiglia, E., Masiero, S., Tikhonoff, V., Giacomello, M., \& Zanette, G. (2011a). Effects of Hypnotic Focused Analgesia on Dental Pain Threshold. International Journal of Clinical and Experimental Hypnosis, 59, 454-468.

https://doi.org/10.1080/00207144.2011.594749

Facco, E., Casiglia, E., Zanette, G., \& Testoni, I. (2018). On the Way of Liberation from Suffering and Pain: Role of Hypnosis in Palliative Care. Annals of Palliative Medicine, 7, 63-74. https://doi.org/10.21037/apm.2017.04.07

Facco, E., Casiglia, E., Zanette, G., Bacci, C., Cavallin, F., \& Manani, G. (2011). The Effects of Hypnosis on Dental Pain Threshold. International Journal of Oral and Maxillofacial Surgery, 40, 1058-1059. https://doi.org/10.1016/j.ijom.2011.07.112

Facco, E., Casiglia, E., Zanette, G., Masiero, S., Bacci, C., Lapenta, A. M., \& Manani, G. (2009). Effects of Hypnosis on Dental Pain Threshold. Preliminary Report. Pain Practice, 9, 47-48.

Facco, E., Ermani, M., Rampazzo, P., Tikhonoff, V., Saladini, M., Zanette, G., Casiglia, E. et al. (2014). Top-Down Regulation of Left Temporal Cortex by Hypnotic Amusia for 
Rhythm: A Pilot Study on Mismatch Negativity. International Journal of Clinical and Experimental Hypnosis, 62, 129-144. https://doi.org/10.1080/00207144.2014.869124

Facco, E., Pasquali, S., Zanette, G., \& Casiglia, E. (2013). Hypnosis as Sole Anaesthesia for Skin Tumour Removal in a Patient with Multiple Chemical Sensitivity. Anaesthesia, 68, 961-965. https://doi.org/10.1111/anae.12251

Facco, E., Testoni, I., Ronconi, L., Casiglia, E., Zanette, G., \& Spiegel, D. (2017). Psychological Features of Hypnotizability: A First Step towards Its Empirical Definition. International Journal of Clinical and Experimental Hypnosis, 65, 98-119. https://doi.org/10.1080/00207144.2017.1246881

Farrer, C., Franck, N., Georgieff, N., Frith, C. D., Decety, J., \& Jeannerod, M. (2003). Modulating the Experience of Agency: A Positron Emission Tomography Study. Neuroimage, 18, 324-333. https://doi.org/10.1016/S1053-8119(02)00041-1

Farrow, T. F., Zheng, Y., Wilkinson, I. D., Spence, S. A., Deakin, J. F., Tarrie, N., Griffiths, P. D. et al. (2001). Investigating the Functional Anatomy of Empathy and Forgiveness. Neuroreport, 12, 2433-2438. https://doi.org/10.1097/00001756-200108080-00029

Freeman, R., Barabasz, A., Barabasz, M., \& Warner, D. (2000). Hypnosis and Distraction Differ in Their Effects on Cold Pressor Pain. American Journal of Clinical Hypnosis, 43, 137-148. https://doi.org/10.1080/00029157.2000.10404266

Fukushima, H., Goto, Y., Maeda, T., Kato, M., \& Umeda, S. (2013). Neural Substrates for Judgment of Self-Agency in Ambiguous Situations. PLoS ONE, 8, e72267. https://doi.org/10.1371/journal.pone.0072267

Giordano, N., Tikhonoff, V., Tosello, M. T., Lapenta, A. M., \& Casiglia, E. (2012). An Experimental Approach to Hypnotic Age Regression: Controlled Study over 10 Healthy Participants. Contemporary Hypnosis \& Integrative Therapy, 29, 271-283.

Glover, G. H. (2011). Overview of Functional Magnetic Resonance Imaging. Neurosurgery Clinics of North America, 22, 133-139. https://doi.org/10.1016/j.nec.2010.11.001

Granone, F. (1962). Hypnotism. Torino: Boringhieri.

Granone, F. (1972). Treatise of Hypnosis (Sofrologia). Torino: Boringhieri.

Granone, F. (1989). Treatise of Hypnosis. Torino: UTET.

Halsband, U., \& Wolf, T. G. (2015). Functional Changes in Brain Activity after Hypnosis in Patients with Dental Phobia. Journal of Physiology Paris, 109, 131-142. https://doi.org/10.1016/j.jphysparis.2016.10.001

Ibrahim, M. M. (1975). Localization of Lesion in Patients with Idiopathic Orthostatic Hypotension. British Heart Journal, 37, 869-872. https://doi.org/10.1136/hrt.37.8.868

Insel, T. R. (2010). Faulty Circuits. Scientific American, 302, 44-51. https://doi.org/10.1038/scientificamerican0410-44

Jamieson, G. A., \& Burgess, A. P. (2014). Hypnotic Induction Is Followed by State-Like Changes in the Organization of EEG Functional Connectivity in the Theta and Beta Frequency Bands in High-Hypnotically Susceptible Individuals. Frontiers in Human Neuroscience, $8,528$.

Kang, S. Y., Im, C. H., Shim, M., Nahab, F. B., Park, J., Kim, D. W., Kakareka et al. (2015). Brain Networks Responsible for Sense of Agency: An EEG Study. PLoS ONE, 10, e0135261. https://doi.org/10.1371/journal.pone.0135261

Kerestes, R., Ladouceur, C. D., Meda, S., Nathan, P. J., Blumberg, H. P., Maloney, K., Ruf, B. et al. (2012). Abnormal Prefrontal Activity Subserving Attentional Control of Emotion in Remitted Depressed Patients during a Working Memory Task with Emotional Distracters. Psychological Medicine, 42, 29-40. 
https://doi.org/10.1017/S0033291711001097

Landry, M., Lifshitz, M., \& Raz, A. (2017). Brain Correlates of Hypnosis: A Systematic Review and Meta-Analytic Exploration. Neuroscience and Biobehavioral Reviews, 81, 75-98.

Lauro, L. J., Tettamanti, M., Cappa, S. F., \& Papagno, C. (2008). Idiom Comprehension: A Prefrontal Task? Cerebral Cortex, 18, 162-170.

Locke, D. E. C. (2013). Interpreting the MMPI-2-RF. The Clinical Neuropsychologist, 27, 339-341. https://doi.org/10.1080/13854046.2012.742291

Loewenstein, R. J. (2018). Dissociation Debates: Everything You Know Is Wrong. Dialogues in Clinical Neuroscience, 20, 229-242.

Longe, O., Maratos, F. A., Gilbert, P., Evans, G., Volker, F., Rockliff, H., \& Rippon, G. (2010). Having a Word with Yourself: Neural Correlates of Self-Criticism and SelfReassurance. Neuroimage, 49, 1849-1856. https://doi.org/10.1016/j.neuroimage.2009.09.019

Lynn, S. J., \& Green, J. P. (2011). The Sociocognitive and Dissociation Theories of Hypnosis: Toward a Rapprochement. International Journal of Clinical and Experimental Hypnosis, 59, 277-293.

Mazza, M., Di Michele, V., Pollice, R., Casacchia, M., \& Roncone, R. (2008). Pragmatic Language and Theory of Mind Deficits in People with Schizophrenia and Their Relatives. Psychopathology, 41, 254-263. https://doi.org/10.1159/000128324

Mazzoni, G., Venneri, A., McGeown, W. J., \& Kirsch, I. (2013). Neuroimaging Resolution of the Altered State Hypothesis. Cortex, 49, 400-410.

https://doi.org/10.1016/j.cortex.2012.08.005

McGeown, W. J., Mazzoni, G., Vannucci, M., \& Venneri, A. (2015). Structural and Functional Correlates of Hypnotic Depth and Suggestibility. Psychiatry Research, 231, 151-159. https://doi.org/10.1016/j.pscychresns.2014.11.015

McGeown, W. J., Mazzoni, G., Venneri, A., \& Kirsch, I. (2009). Hypnotic Induction Decreases Anterior Default Mode Activity. Consciousness and Cognition, 18, 848-855. https://doi.org/10.1016/j.concog.2009.09.001

McGeown, W. J., Venneri, A., Kirsch, I., Nocetti, L., Roberts, K., Foan, L., \& Mazzoni, G. (2012). Suggested Visual Hallucination without Hypnosis Enhances Activity in Visual Areas of the Brain. Consciousness and Cognition, 21, 100-116. https://doi.org/10.1016/j.concog.2011.10.015

Nahab, F. B., Kundu, P., Gallea, C., Kakareka, J., Pursley, R., Pohida, T., Miletta, N. et al. (2011). The Neural Processes Underlying Self-Agency. Cerebral Cortex, 21, 48-55. https://doi.org/10.1093/cercor/bhq059

Oakley, D., Deeley, Q., \& Halligan, P. (2007). Hypnotic Depth and Response to Suggestion under Standardized Conditions and during fMRI Scanning. International Journal of Clinical and Experimental Hypnosis, 55, 32-58. https://doi.org/10.1080/00207140600995844

Peckerman, A., Hurwitz, B. E., Saab, P. G., Llabre, M. M., MacCabe, P. M., \& Schneiderman, N. (1994). Stimulus Dimension of the Cold Pressor Test and the Associated Patterns of Cardiovascular Response. Psychophysiology, 31, 282-290. https://doi.org/10.1111/j.1469-8986.1994.tb02217.x

Peckerman, A., Saab, P. G., McCabe, P. M., Skyler, J. S., Winters, R. W., Llabre, M. M., \& Schneiderman, N. (1991). Blood Pressure Reactivity and Perception of Pain during the Forhead Cold Pressor Test. Psychophysiology, 28, 485-495.

https://doi.org/10.1111/j.1469-8986.1991.tb01985.x 
Priftis, K., Schiff, S., Tikhonoff, V., Giordano, N., Amodio, P., Umiltà, C., \& Casiglia, E. (2011). Hypnosis Meets Neurosciences: Simulating Visuospatial Neglect in Healthy Participants. Nuropsychologia, 49, 3346-3350.

https://doi.org/10.1016/j.neuropsychologia.2011.08.008

Pyka, M., Burgmer, M., Lenzen, T., Pioch, R., Dannlowski, U., Pfleiderer, B., Ewert, A. W. et al. (2011). Brain Correlates of Hypnotic Paralysis-A Resting-State fMRI Study. Neuroimage, 56, 2173-2182. https://doi.org/10.1016/j.neuroimage.2011.03.078

Ray, W., \& Oathes, D. (2003). Brain Imaging Techniques. International Journal of Clinical and Experimental Hypnosis, 51, 97-104. https://doi.org/10.1076/iceh.51.2.97.14616

Solms, M. (2017). What Is "the Unconscious" and Where Is It Located in the Brain? A Neuropsychoanalytic Perspective. Annals of the New York Academy of Sciences, 1406, 90-97. https://doi.org/10.1111/nyas.13437

Stikova, E. (2012). Magnetic Resonance Imaging Safety: Principles and Guidelines. Prilozi, 33, 441-472.

Stolarz, K., Staessen, J. A., Kawecka-Jaszcz, K., Brand, E., Bianchi, G., Kuznetsova, T., Tikhonoff, T. et al. (2004). Genetic Variation in CYP11B2 and AT1R Influences Heart Rate Variability Conditional on Sodium Excretion. Hypertension, 44, 156-162. https://doi.org/10.1161/01.HYP.0000135846.91124.a5

Tikhonoff, V., Azzi, D., Boschetti, G., Giordano, N., Rempelou, P., Giacomello, M., Tosello, M. T. et al. (2012). Increase of Isometric Performance via Hypnotic Suggestion: Experimental Study over 10 Young Healthy Volunteers. Contemporary Hypnosis \& Integrative Therapy, 29, 352-262.

Tikhonoff, V., Kuznetsova, T., Stolarz, L., Bianchi, G., Casiglia, E., Kawecka-Jaszcz, K., Nikitin, Y. et al. (2003). $\beta$-Adducin Polymorphism, Blood Pressure, and Sodium Excretion in Three European Populations. American Journal of Hypertension, 16, 840-846. https://doi.org/10.1016/S0895-7061(03)00975-0

Tikhonoff, V., Senzolo, M., Lapenta, A. M., Palatini, P., \& Casiglia, E. (2018). Hypnotic Hallucination of Body Heating Modifies Splanchnic Circulation: Haemodynamic and Ultrasonographic. Pilot Study in Normal Volunteers. Sleep and Hypnosis, 20, 31-39.

Wall, T. W. (2018). Hypnosis: A Psychodynamic Perspective. American Journal of Clinical Hypnosis, 60, 218-238.

Wickramasekera, I. E. (2015). Mysteries of Hypnosis and the Self Are Revealed by the Psychology and Neuroscience of Empathy. American Journal of Clinical Hypnosis, 57, 330-348. 